\title{
Anti-Inflammatory Activity of the Total Flavonoid Fraction from Broussonetia papyrifera in Combination with Lonicera japonica
}

\author{
Jeong Ho JIN ${ }^{1}$, Hyun LIm${ }^{1}$, Soon Youl KwoN ${ }^{2}$, Kun Ho SoN ${ }^{2}$, and Hyun Pyo KIm ${ }^{1, *}$ \\ ${ }^{1}$ College of Pharmacy, Kangwon National University, Chunchon 200-701, ${ }^{2}$ Department Food and Nutrition, \\ Andong National University, Andong 760-749, Republic of Korea
}

(Received March 12, 2010; Revised April 8, 2010; Accepted April 9, 2010)

\begin{abstract}
To establish the anti-inflammatory activity of the total flavonoid fraction of the root barks of Broussonetia papyrifera (EBP) and a new formula, the ethanol extract of the root barks of $B$. papyrifera was fractionated with ethylacetate, yielding the hydrophobic prenylated flavonoid-enriched fraction. EBP and the ethanol extract of the whole Lonicera japonica (ELJ) plant were then mixed at a ratio of 1:1 (w/w) to give a new preparation $(\mathrm{BL})$ in the hope of obtaining an optimal formula with a higher anti-inflammatory activity. Evaluation of the effects of these preparations on A23187-treated rat basophilic leukemia (RBL-1) cells revealed that EBP potently inhibited 5-lipoxygenase (5-LOX), while ELJ showed weak inhibition. Additionally, the mixture $(\mathrm{BL})$ clearly showed stronger inhibitory effects against 5-LOX than either preparation alone. These preparations also inhibited cyclooxygenase-2-catalyzed $\mathrm{PGE}_{2}$ and inducible nitric oxide (NO) synthase-catalyzed NO production by lipopolysaccharide-treated RAW 264.7 cells. When tested against arachidonic acid-induced mouse ear edema, EBP showed strong inhibitory activity at doses of $5-200 \mathrm{mg} / \mathrm{kg}$ when administered orally, but BL had obviously stronger inhibitory effects. When tested against $\lambda$-carrageenaninduced paw edema in mice, BL showed a potent and synergistic anti-inflammatory effect. In addition, in the acetic acid-induced writhing test, BL was found to have strong analgesic activity at $50-400 \mathrm{mg} / \mathrm{kg}$. Taken together, these results indicate that each of these preparations exert anti-inflammatory activity in vitro and in vivo. In particular, BL showed stronger anti-inflammatory activity than EBP, and these anti-inflammatory effects were partially related to the inhibition of eicosanoid and NO production. BL may be useful for the treatment of human inflammatory disorders.
\end{abstract}

Keywords: Broussonetia papyrifera, Lonicera japonica, Flavonoid, Anti-inflammation, Lipoxygenase

\section{INTRODUCTION}

Broussonetia papyrifera (L.) Vent. (Moraceae) is widely distributed in China, Japan and Korea. The root bark of this plant has long been used as an anti-inflammatory, antibronchitis and antitussive agent in traditional Chinese medicine (Editorial Committee, 1999). Previously, the radix of $B$. papyrifera was shown to have PTP1B and tyrosinase inhibitory activities (Chen et al., 2002; Hwang and Lee, 2007). Recently, the $95 \%$ ethanol extracts of the radix, stems, leaves and fruits of $B$. papyrifera showed antinociceptive and anti-inflammatory activity in vivo, with the radix having the strongest activity (Lin et al., 2008).

${ }^{*}$ Corresponding author

Tel: +82-33-250-6915 Fax: +82-33-255-7865

E-mail: hpkim@kangwon.ac.kr
Moreover, it has been suggested that these anti-inflammatory effects are partially related to the inhibition of vascular permeability via autocrines and nitric oxide.

Several prenylated flavonoids including papyriflavonol A and broussochalcone $A$ have been successfully isolated from the root barks of this plant material (Son et al., 2001). Among these, papyriflavonol $A$ was found to be a relatively specific 5-lipoxygenase (5-LOX) inhibitor (Chi et al., 2001b). Moreover, broussochalcone A was found to suppress inducible nitric oxide synthase (iNOS) in macrophages (Cheng et al., 2001). In addition, papyriflavonol A has been shown to inhibit allergic response in vivo (Kwak et al., 2003b). Because 5-LOX inhibitors have the potential for use in the treatment of inflammatory disorders such as bronchial asthma and bronchitis, and because iNOS inhibitors may also be used as anti-inflammatory agents, the 
prenylated flavonoid-enriched fraction from the root barks of $B$. papyrifera (EBP) was prepared and its effects on several inflammatory models were examined in this study.

Lonicera japonica (Thunb.) (Caprifoliaceae) is a twining shrub that has long been used as an antidote and to treat urinary disorders, fever, and headache (Shougakukan, 1985). Additionally, Lonicera japonica has been used as an anti-inflammatory agent in Korea since ancient times and is widely used for the treatment of upper respiratory tract infections, diabetes mellitus, and rheumatoid arthritis (Lee et al., 1998). Various constituents have been isolated from the total plant materials, including lonicerosides and iridoids, and their anti-inflammatory activities have been evaluated (Lee et al., 1995; Kwak et al., 2003a; Qian et al., 2007). To develop a new anti-inflammatory herbal drug, the ethanol extract (ELJ) was examined for its in vitro and in vivo activity in animal models of inflammation. In addition, a new formulation (BL) composed of EBP and ELJ $(1: 1, w / w)$ was prepared and its anti-inflammatory activity was examined in the present investigation with the hope of obtaining a stronger anti-inflammatory effect.

\section{MATERIALS AND METHODS}

\section{Chemicals}

A23187, N-[2-cyclohexyloxy-4-nitrophenyl]methane sulfonamide (NS-398) was obtained from Biomol (Plymouth Meeting, PA). 2-Amino-5,6-dihydro-6-methyl-4H-1,3-thiazine hydrochloride (AMT) was purchased from Tocris Cookson Ltd. (UK). Arachidonic acid (AA, 99\%), 3-(4,5-dimethylthiazol-2-yl)-2,5-diphenyltetrazolium bromide (MTT), nordihydroguaiaretic acid (NDGA), prednisolone, indomethacin, aspirin and lipopolysaccharide (LPS, Escherichia coli 0127:B8) were purchased from Sigma Chemical Co. (St. Louis, MO). DMEM and other cell culture reagents including FBS were products of Gibco BRL (Grand Island, NY). A protein assay kit was purchased from Bio-Rad (Hercules, CA).

\section{Animals}

Male Sprague-Dawley (SD) rats and ICR mice (4 weeks old, specific pathogen-free) were obtained from Orient-Bio Co. (Korea). Animals were fed with standard lab. chow and water ad libitum. The animals were maintained in the animal facility (KNU) at $20-22^{\circ} \mathrm{C}$ under $40-60 \%$ relative humidity and a $12 \mathrm{~h} / 12 \mathrm{~h}$ (light/dark) cycle for at least 7 days prior to the experiment. The experimental design using the animals was approved by the local committee for animal experimentation, KNU (KIACUC-09-0012). In addition, the ethical guidelines described in the KFDA Guide for the Care and Use of Laboratory Animals was followed throughout the experiments.

\section{Plant materials}

B. papyrifera was collected in the southern part (near Andong) of the Korean peninsula, authenticated by one of the authors, Dr. K. H. Son (Andong National University) and a voucher specimen was deposited in Andong National University. The dried root barks of $B$. papyrifera were chopped and extracted with $100 \%$ ethanol. The ethanol extract was then dried under vacuum and the resulting extract was dissolved in water. The solution was then fractionated with ethylacetate. The ethylacetate fraction was subsequently dried, and this dried fraction (EBP) was used throughout the experiment. The final yield for EBP was approximately $4.2 \%(\mathrm{w} / \mathrm{w})$. Papyriflavonol $\mathrm{A}$ and broussochalcone $A$ (Fig. 1) were isolated from this fraction as previously described (Son et al., 2001). The whole plant of $L$. japonica was purchased from a local herbal market, authenticated by Dr. K. H. Son and a voucher specimen was deposited in Andong National University. The dried plant was then chopped and extracted with $70 \%$ ethanol. The ethanol extract was then dried under vacuum and this dried extract (ELJ) was used throughout the experiment.

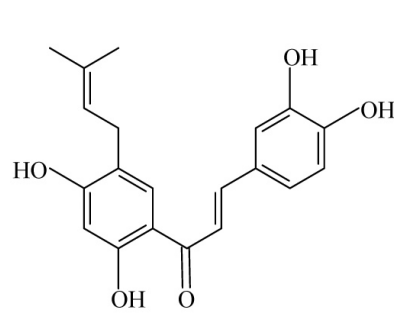

Broussochalcone A

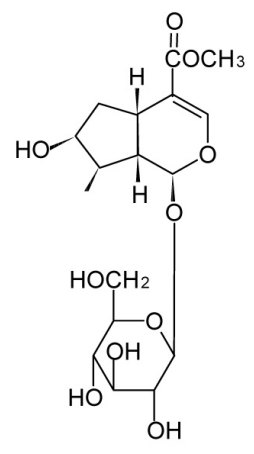

Loganin<smiles>CC(C)=CCc1cc(-c2oc3cc(O)c(CC=C(C)C)c(O)c3c(=O)c2O)cc(O)c1O</smiles>

Papyriflavonol A

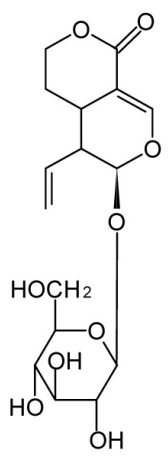

Sweroside
Fig. 1. Chemical structures of the major constituents of $B$. papyrifera and $L$. japonica. 
The yield of ELJ was approximately $9.7 \%$ (w/w). Loganin and sweroside were isolated from this extract as previously described (Kawai et al., 1988). BL was a mixture of EBP and ELJ (1:1, w/w).

The contents of the prenylated flavonoids (papyriflavonol $A$ and broussochalcone $A$ ) in EBP and the iridoids (loganin and sweroside) in ELJ were determined by HPLC analysis. EBP (10 mg) and ELJ (10 mg) were dissolved in MeOH (1 $\mathrm{ml})$, filtered through a syringe filter $(0.45 \mu \mathrm{m})$ and aliquots were injected to HPLC. The typical chromatograms are shown in Fig. 2. The contents of papyriflavonol $A$ and broussochalcone $A$ were found to be $0.33 \%$ and $1.03 \%$, respectively. The contents of loganin and sweroside were found to be $4.19 \%$ and $3.30 \%$, respectively.

\section{Rat basophilic leukemia-1 (RBL-1) cell culture and measurement of leukotrienes (LT)}

To evaluate the 5-LOX inhibitory activity, RBL-1 cells pur- chased from the American Type Culture Collection (ATCC, Rockville, VA) were cultured in RPMI 1640 with $10 \%$ FBS, $2 \mathrm{mM}$ glutamine and $1 \%$ antibiotics under $5 \% \mathrm{CO}_{2}$ at $37^{\circ} \mathrm{C}$. The cells were then incubated in 96-well plates for $2 \mathrm{~h}$. The test compounds were dissolved in DMSO and diluted to appropriate concentrations with serum-free DMEM. The final concentration of DMSO was adjusted to $0.1 \%(\mathrm{v} / \mathrm{v})$. The cells were then pre-incubated with the test compounds for $10 \mathrm{~min}$. The cell viability was assessed using an MTT assay as previously described (Mossman, 1983). A-23187 (ionophore, $3 \mu \mathrm{M}$ ) was then added to activate the 5-LOX and the cells were incubated for $15 \mathrm{~min}$ as previously described, with slight modification (Tries et al., 2002). The media was then collected and the concentration of the 5-LOX product, cysteinyl leukotrienes $\left(\mathrm{LTC}_{4} / \mathrm{D}_{4} / \mathrm{E}_{4}\right)$, was measured using an ELISA kit (Cayman Chem, Ann Arbor, Michigan, USA) as recommended by the manufacturer. (a)

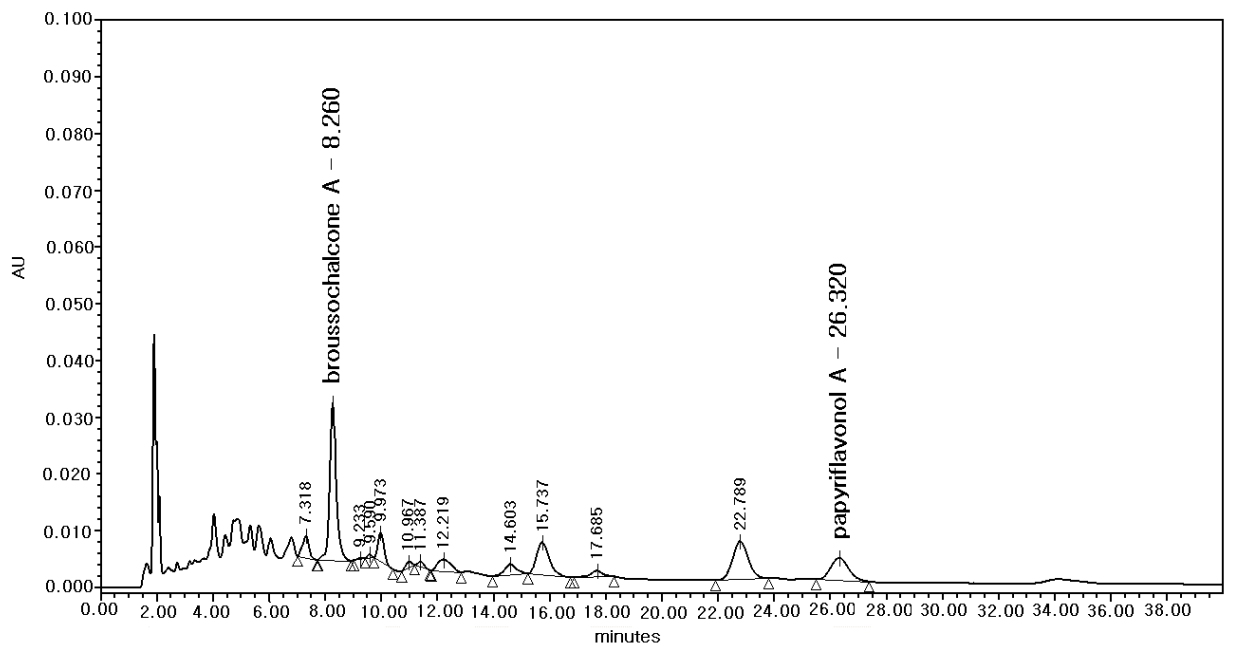

(b)

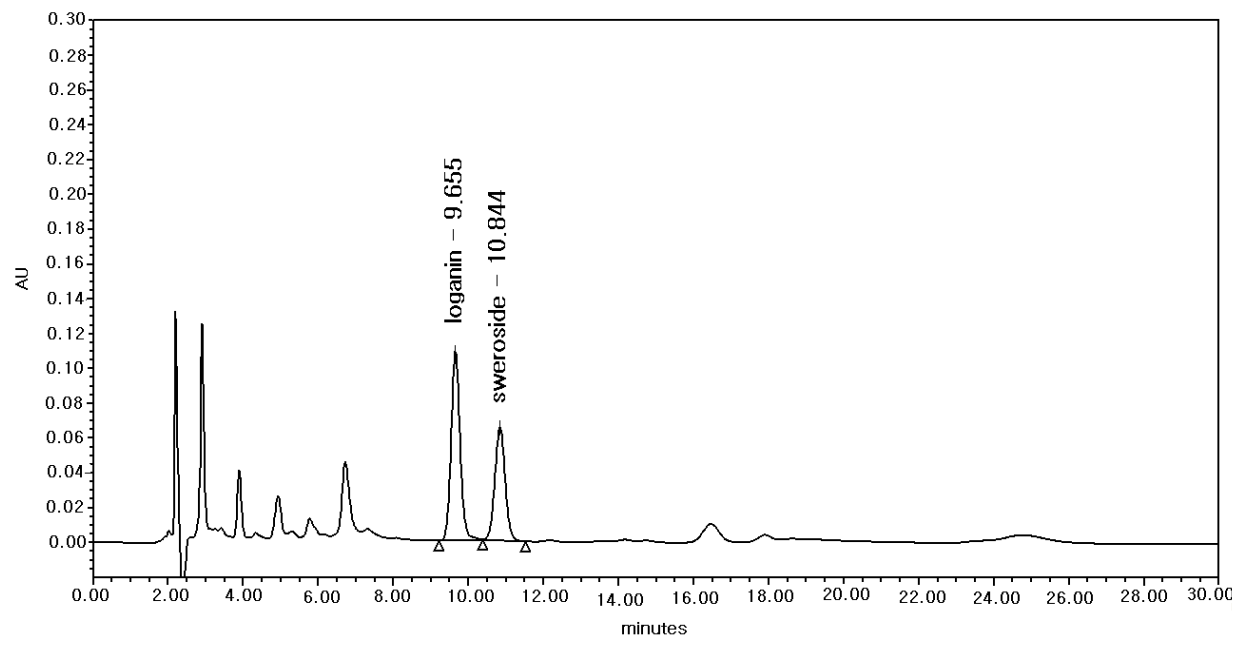

Fig. 2. Typical HPLC chromatogram of EBP and ELJ. (a) Chromatogram of EBP, (b) Chromatogram of ELJ. EBP analysis: Alliance 2695 separation module (Waters), Grom-sil C-18 column $4 \times 150$ (CROM), $5 \mu \mathrm{m}$, mobile phase: tetrahydrofuran: $\mathrm{H}_{2} \mathrm{O}$, pH 3.0 (47:53); flow rate: $0.6 \mathrm{ml} / \mathrm{min}, \mathrm{UV}: 390 \mathrm{~nm}$. ELJ analysis: mobile phase: acetonitrile: $\mathrm{H}_{2} \mathrm{O}, \mathrm{pH} 3.0$ (13:87), UV: $239 \mathrm{~nm}$. 


\section{RAW 264.7 cell culture and measurement of $\mathrm{NO}$ and $\mathrm{PGE}_{2}$ concentrations}

RAW 264.7 cells were obtained from ATCC and cultured in DMEM supplemented with $10 \%$ FBS and $1 \%$ antibiotics (100 U/ml penicillin and $100 \mu \mathrm{g} / \mathrm{ml}$ streptomycin) under $5 \%$ $\mathrm{CO}_{2}$ at $37^{\circ} \mathrm{C}$. The cells were then activated with lipopolysaccharide (LPS) as previously described (Chi et al., 2001a). Briefly, cells were plated in 96-well plates $\left(2 \times 10^{5}\right.$ cells/well) and then pre-incubated for $2 \mathrm{hr}$, after which the test compounds and LPS $(1 \mu \mathrm{g} / \mathrm{ml})$ were added and the samples were incubated for an additional $24 \mathrm{~h}$ unless otherwise specified. The $\mathrm{PGE}_{2}$ concentration in the medium was then measured using an ELISA kit for $\mathrm{PGE}_{2}$ (Cayman Chem. Co., Ann Arbor, Michigan, USA) according to the manufacturer's recommendations. To assess the NO production, the stable conversion product of $\mathrm{NO}$, nitrite $\left(\mathrm{NO}_{2}{ }^{-}\right)$, was measured using Griess reagent based on the optical density at $550 \mathrm{~nm}$.

\section{Western blot analysis}

To measure the protein levels of cyclooxygenase-2 (COX-2) and iNOS, Western blotting technique were used (Chi et al., 2001a). RAW 264.7 cells were cultured in 6-well plates $\left(5 \times 10^{6}\right.$ cells/well $)$ in the presence or absence of LPS $(1 \mu \mathrm{g} / \mathrm{ml})$ with/without test compounds for $16-20 \mathrm{~h}$. After cell homogenates were prepared, the supernatant was obtained by centrifugation at $15,000 \mathrm{~g}$ for $30 \mathrm{~min}$. Using Tris-glycine gels $(8 \%)$, electrophoresis was carried out and bands were blotted to PVDF membranes. The membranes were incubated with COX-2 antibody (No-160116, Cayman Chem., Ann Arbor, Michigan, USA) and iNOS antibody (N32030, Transduction Lab.) and the bands were visualized by chemiluminescent reagent (Amersham, UK). Band thickness was scanned using Image J (NIH, Bethesda, Maryland, USA).

\section{AA-induced ear edema in mice}

In order to evaluate the inhibitory activity against animal model of inflammation, mouse AA-induced ear edema was employed. According to previously described procedure (Kim et al., 1993), 2\% AA in acetone was topically applied to the ears of mice $(20 \mu \mathrm{l} / \mathrm{ear})$. One hour later, the ear thickness was measured using a dial thickness gauge (Mitutoyo, Japan). The test compounds dissolved in DMSO:water (1:1) were administered orally $(0.1 \mathrm{ml} /$ mouse $)$ $1 \mathrm{~h}$ prior to AA treatment.

\section{$\lambda$-Carrageenan (CGN)-induced paw edema in mice}

For establishing anti-inflammatory activity, mouse CGNinduced paw edema assay was also used with slight modification of Winter et al. (1962). Test compounds were administered orally to mice. One hour later, $1 \%$ CGN (w/v) dissolved in pyrogen-free sterile saline solution (0.05 $\mathrm{ml} /$ paw) was injected to right hind paw and, after $5 \mathrm{~h}$, paw volume was measured using plenthysmometer (Ugo Basil, Italy). The paw volume increased from the initial non-treated paw volume was regarded as edema.

\section{Acetic acid-induced writhing in mice}

To measure the analgesic activity, $1 \%$ acetic acid (100 $\mu$ l) was injected intraperitoneally to mice. At $10 \mathrm{~min}$ after acetic acid injection, the number of writhings were counted for 10 min. Test compounds dissolved in DMSO:water (1:1) were orally administered $(0.1 \mathrm{ml} /$ mouse $) 1 \mathrm{~h}$ prior to acetic acid injection.

\section{Statistical analysis}

Experimental values were represented as arithmetic mean \pm SD. One-way analysis of variance (ANOVA), followed by Dunnett's test was used to determine the statistical significance.

\section{RESULTS}

\section{Anti-inflammatory activity in vitro}

It is well known that high amounts of cysteinyl-LTs are produced by 5 -LOX when RBL-1 cells were activated with

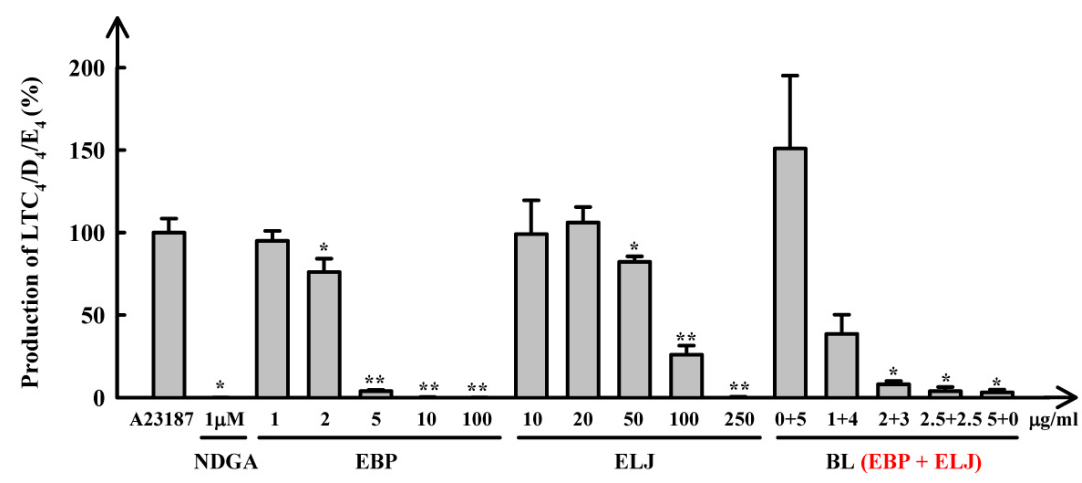

Fig. 3. Effects on 5-LOX-mediated LT production from A23187-treated RBL-1 cells. RBL-1 cells were cultured, and A23187 with/without test compounds was added to activate 5-LOX. After 15 min, cysteinyl-LTs were measured in the media. $\mathrm{n}=3,{ }^{*} p<0.05,{ }^{* *} p<0.01$, significantly different from the A23187-treated control group. 
A23187 (calcium ionophore). In this study, RBL-1 cells produced $1,109.5 \pm 93.6 \mathrm{pg} / \mathrm{ml} \mathrm{LTC}_{4} / \mathrm{D}_{4} / \mathrm{E}_{4}$ for $15 \mathrm{~min}$ incubation period, while the basal level was $4.2 \pm 1.2 \mathrm{pg} / \mathrm{ml}$ for $15 \mathrm{~min}(\mathrm{n}=3)$. Under these conditions, EBP potently and concentration-dependently inhibited 5-LOX (Fig. 3). The
$\mathrm{IC}_{50}$ value was found to be $3.1 \mu \mathrm{g} / \mathrm{ml}$. On the other hand, ELJ only weakly inhibited 5-LOX $\left(\mathrm{IC}_{50}=78.7 \mu \mathrm{g} / \mathrm{ml}\right)$. However, the mixture of EBP + ELJ showed potent inhibition $\left(\mathrm{IC}_{50}<1 \mu \mathrm{g} / \mathrm{ml}\right.$ based on the weight of EBP). When compared with the simple addition of the inhibitory activity

(a)

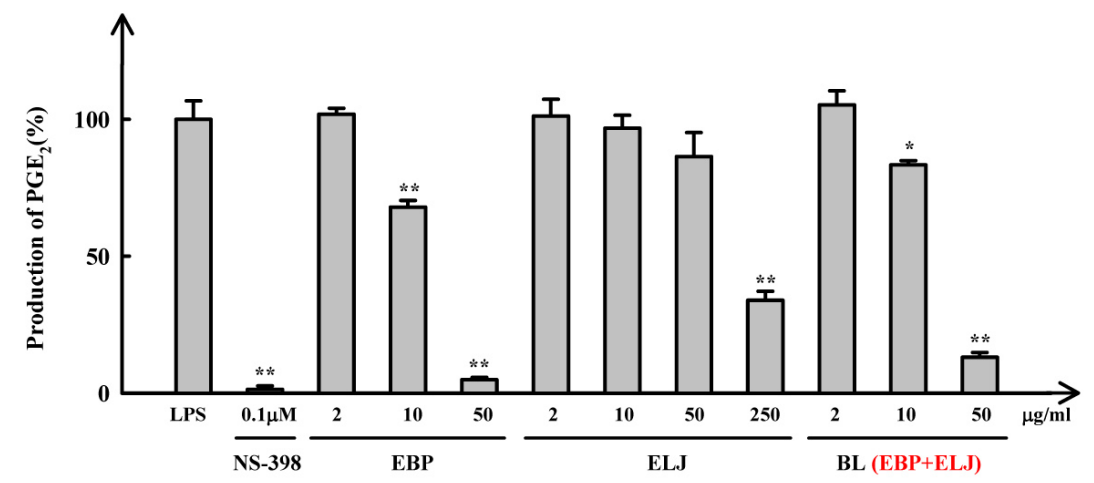

(b)

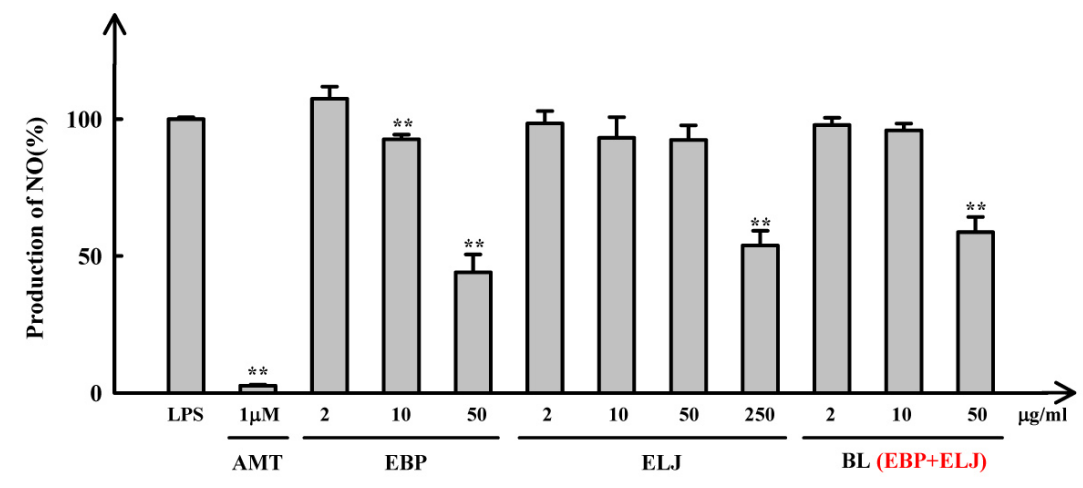

(c)
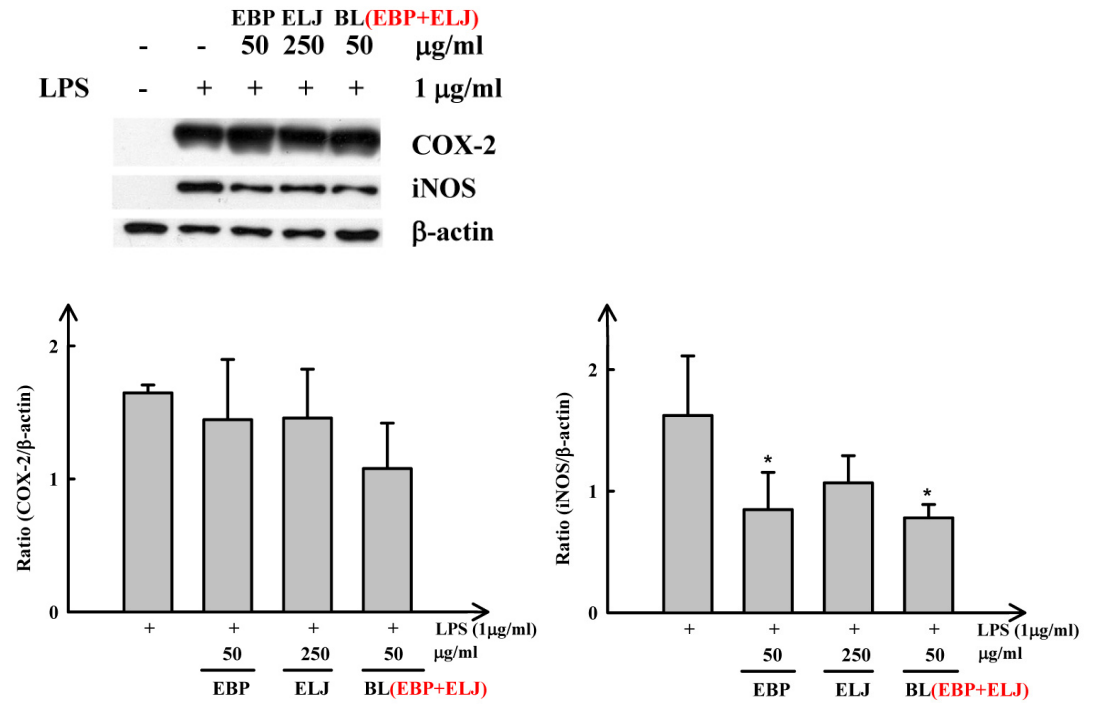

Fig. 4. Effects on $\mathrm{PGE}_{2}$ and $\mathrm{NO}$ production from LPS-treated RAW 264.7 cells. (a) COX-2-catalyzed $\mathrm{PGE}_{2}$ production, (b) iNOS-catalyzed NO production, (c) effects on COX-2 and iNOS expression (Western blot), RAW 264.7 cells were incubated with LPS in the presence or absence of test compounds. After $24 \mathrm{~h}, \mathrm{PGE}_{2}$ and $\mathrm{NO}$ concentrations were measured from the media. For the Western blot analysis, RAW 2654. 7 cells were incubated with LPS in the presence or absence of test compounds for 16-20 h. LPS-treated group produced $120.0 \pm 8.0 \mathrm{nM} \mathrm{PGE}_{2}$ and $32.7 \pm 0.2 \mu \mathrm{M}$ NO (Basal levels were $1.2 \pm 0.4$ $\mathrm{nM}$ and $0.8 \pm 0.3 \mu \mathrm{M}$, respectively.). $\mathrm{n}=3,{ }^{*} p<$ $0.05,{ }^{* *} p<0.01$, significantly different from the LPS-treated control group. 
of the same amounts of each material, the mixture demonstrated a stronger inhibitory effect on 5-LOX, suggesting that the mixture had a synergistic effect. Especially at 2.5 $+2.5 \mu \mathrm{g} / \mathrm{ml}$ of EBP + ELJ (BL, 1:1 mixture), BL showed almost complete inhibition of 5-LOX-mediated LT production $(96.1 \%)$. From these results, $\mathrm{BL}$ among varying ratios of the mixtures was selected for further characterization. NDGA (LOX inhibitor) used as a reference compound also inhibited 5-LOX strongly (99\% inhibition at $1 \mu \mathrm{M})$.

In addition, EBP and BL significantly inhibited COX-2-catalyzed $\mathrm{PGE}_{2}$ and iNOS-catalyzed $\mathrm{NO}$ production from LPS-treated RAW 264.7 cells, a mouse macrophage cell line at concentrations of up to $50 \mu \mathrm{g} / \mathrm{ml}$ (Fig. 4a and 4b). The $\mathrm{IC}_{50}$ values of EBP and BL were 21.4 and $29.0 \mu \mathrm{g} / \mathrm{ml}$ for $\mathrm{PGE}_{2}$ production, and 45.1 and $59.4 \mu \mathrm{g} / \mathrm{ml}$ for NO production, respectively. The effects of the preparations on the expression levels of COX-2 and iNOS were examined at concentrations showing significant inhibition of $\mathrm{PGE}_{2}$ and NO production. As shown in Fig. 4c, EBP $(50 \mu \mathrm{g} / \mathrm{ml})$, ELJ $(250 \mu \mathrm{g} / \mathrm{ml})$ and $\mathrm{BL}(50 \mu \mathrm{g} / \mathrm{ml})$ reduced iNOS induction. In contrast, EBP, ELJ and BL only weakly inhibited COX-2 expression, but not statistically significant.

\section{Anti-inflammatory activity in vivo}

For elucidating in vivo anti-inflammatory activity against animal models of inflammation, mouse AA-induced ear edema test and CGN-induced paw edema test were employed. In AA-induced ear edema, EBP and ELJ in-

Table I. Inhibition of arachidonic acid (AA)-induced mouse ear edema

\begin{tabular}{lcl}
\hline Compounds & Dose $(\mathrm{mg} / \mathrm{kg})$ & $\begin{array}{c}\text { Ear thickness } \\
\text { increased, } \mathrm{mm}\end{array}$ \\
\hline AA-treated & - & $0.070 \pm 0.010^{\mathrm{a}}(-)^{\mathrm{b}}$ \\
Indomethacin & 20 & $0.021 \pm 0.013^{\mathrm{c}}(70.0)$ \\
EBP & 50 & $0.050 \pm 0.037(28.6)$ \\
& 100 & $0.032 \pm 0.015^{\mathrm{c}}(54.3)$ \\
ELJ & 200 & $0.038 \pm 0.023^{\mathrm{c}}(45.7)$ \\
& 50 & $0.090 \pm 0.034(-)$ \\
BL (EBP+ELJ) & 100 & $0.054 \pm 0.017(22.9)$ \\
& 200 & $0.053 \pm 0.025(25.0)$ \\
& $50(25+25)$ & $0.064 \pm 0.029(8.6)$ \\
& $200(50+50)$ & $0.046 \pm 0.015^{\mathrm{C}}(34.3)$ \\
& $400(200+200)$ & $0.015 \pm 0.013^{\mathrm{c}}(78.6)$ \\
\hline
\end{tabular}

All compounds dissolved in DMSO:water (1:1) were administered orally. Negative control group without AA treatment showed $0.003 \pm 0.001 \mathrm{~mm}$ increase (The thickness of the untreated ears was $0.190 \pm 0.011 \mathrm{~mm}$ ). ${ }^{\mathrm{a}} \mathrm{n}=5$ (arithmetic mean $\pm \mathrm{SD}$ ), ${ }^{\mathrm{b}} \%$ inhibition compared to the AA-treated control groupm, ${ }^{c} p<0.05$, significantly different from the AA-treated control group. hibited the edematic response at $50-200 \mathrm{mg} / \mathrm{kg}$ by oral administration, with EBP being more potent, as expected (Table I). In the same model, BL showed higher inhibitory activity compared to the simple addition of the percent inhibition of each extract at 100 and $400 \mathrm{mg} / \mathrm{kg}$. Especially at $400 \mathrm{mg} / \mathrm{kg}$, BL potently inhibited the edematic response ( $>70 \%$ inhibition), which was similar to the results ob-

Table II. Inhibition of carrageenan (CGN)-induced mouse paws edema

\begin{tabular}{lcc}
\hline Compounds & Dose $(\mathrm{mg} / \mathrm{kg})$ & Paw volume increased, ml \\
\hline CGN-treated & - & $0.152 \pm 0.022^{\mathrm{a}}(-)^{\mathrm{b}}$ \\
Indomethacin & 20 & $0.116 \pm 0.039(23.7)$ \\
& 100 & $0.084 \pm 0.019^{\mathrm{C}}(44.7)$ \\
Prednisolone & 20 & $0.076 \pm 0.011^{\mathrm{c}}(50.0)$ \\
EBP & 200 & $0.116 \pm 0.045(23.7)$ \\
ELJ & 200 & $0.134 \pm 0.047(11.8)$ \\
BL (EBP+ELJ) & $50(25+25)$ & $0.136 \pm 0.030(10.5)$ \\
& $100(50+50)$ & $0.120 \pm 0.047(21.1)$ \\
& $200(100+100)$ & $0.100 \pm 0.020^{\mathrm{C}}(34.2)$ \\
& $400(200+200)$ & $0.080 \pm 0.050^{\mathrm{C}}(47.4)$ \\
\hline
\end{tabular}

All compounds dissolved in DMSO:water (1:1) were administered orally. The paw volume of negative control group without CGN treatment was $0.149 \pm 0.025 \mathrm{ml} .{ }^{a} \mathrm{n}=5$ (arithmetic mean \pm $\mathrm{SD}),{ }^{b} \%$ inhibition compared to the CGN-treated control group, ${ }^{c} p<0.05$, significantly different from the CGN-treated control group.

Table III. Inhibition of acetic acid-induced writhings in mice

\begin{tabular}{lcc}
\hline Compounds & Dose $(\mathrm{mg} / \mathrm{kg})$ & Numbers of writhings \\
\hline Exp. 1 & & \\
Acetic acid-treated & - & $14.5 \pm 6.4^{\mathrm{a}}(-)^{\mathrm{b}}$ \\
Aspirin & 100 & $5.7 \pm 3.8^{\mathrm{c}}(60.9)$ \\
EBP & 50 & $12.2 \pm 5.2(16.1)$ \\
& 100 & $8.5 \pm 3.6(41.4)$ \\
& 200 & $7.5 \pm 5.2(48.3)$ \\
ELJ & 100 & $8.2 \pm 5.1(43.7)$ \\
& 200 & $5.8 \pm 4.4^{\mathrm{C}}(59.8)$ \\
BL (EBP+ELJ) & $50(25+25)$ & $8.8 \pm 5.9(39.1)$ \\
& $100(50+50)$ & $7.7 \pm 4.0(47.1)$ \\
& $200(100+100)$ & $7.3 \pm 5.8^{(49.4)}$ \\
& $400(200+200)$ & $4.5 \pm 3.3^{\mathrm{c}}(69.0)$ \\
Exp. 2 & & \\
Acetic acid-treated & - & $17.8 \pm 6.1(-)$ \\
Aspirin & 100 & $9.6 \pm 3.2^{\mathrm{c}}(46.1)$ \\
BL (EBP+ELJ) & $100(50+50)$ & $11.6 \pm 6.4(34.8)$ \\
& $200(100+100)$ & $10.8 \pm 5.5(39.3)$ \\
& $400(200+200)$ & $8.6 \pm 4.3^{\mathrm{c}}(51.7)$ \\
\hline
\end{tabular}

All compounds dissolved in DMSO:water (1:1) were administered orally. ${ }^{a} n=6$ (arithmetic mean $\pm S D$ ), ${ }^{b} \%$ inhibition compared to the acetic acid-treated control group, ${ }^{c} p<0.05$, significantly different from the acetic acid-treated control group. 
tained when indomethacin $(20 \mathrm{mg} / \mathrm{kg})$ was used. Against CGN-induced paw edema, BL also showed dose-dependent inhibition at $50-400 \mathrm{mg} / \mathrm{kg}$, p.o. (Table II). BL showed $47.4 \%$ inhibition at $400 \mathrm{mg} / \mathrm{kg}$, while EBP and ELJ showed $23.7 \%$ and $11.8 \%$ inhibition at $200 \mathrm{mg} / \mathrm{kg}$ (The sum is $35.5 \%$ inhibition at $400 \mathrm{mg} / \mathrm{kg}$ ), indicating the synergistic action of $\mathrm{BL}$.

When the analgesic activity was examined, BL strongly and dose-dependently inhibited acetic acid-induced writhings in mice at 50-400 mg/kg, p.o. (Table III).

\section{DISCUSSION}

The present investigation clearly demonstrated that the EBP, ELJ and a 1:1 mixture of EBP and ELJ (BL) possess anti-inflammatory and analgesic activity. Among these preparations, BL showed the strongest and synergistic inhibitory action, and its in vivo potencies were comparable to those of the currently-used potent anti-inflammatory drugs, indomethacin and prednisolone. Therefore, these results strongly suggest that $B L$ has the potential for treating human inflammatory disorders.

Recently, several parts of $B$. papyrifera were evaluated for their analgesic and anti-inflammatory activities (Lin et al., 2008). They found that the ethanol extracts of the radix, leaves and fruits exerted in vivo activity at $600-2,000$ $\mathrm{mg} / \mathrm{kg}$, p.o. Although these previous results also demonstrated that, among the extracts, the radix showed the most comparable activity, our preparations (EBP and $\mathrm{BL}$ ) had much higher in vivo anti-inflammatory activities at $50-400 \mathrm{mg} / \mathrm{kg}$. Thus, these findings may support the research rational of our study to prepare flavonoid-enriched fraction of the radix of $B$. papyrifera.

Previously, we demonstrated that the prenylated flavonoids from $B$. papyrifera, including papyriflavonol $A$, inhibited 5- and 12-LOX, and that these compounds were more selective for 5-LOX (Chi et al., 2001b). Additionally, broussochalcone $A$ was found to down-regulate iNOS expression and inhibit respiratory bursts in neutrophils (Wang et al., 1997; Cheng et al., 2001). Based on these results, EBP and BL were prepared in the present investigation and they also potently inhibit 5-LOX. Furthermore, 5-LOX inhibitory activity of EBP was considerably enhanced by an addition of ELJ. These preparations (EBP and $\mathrm{BL}$ ) were also found to inhibit iNOS-catalyzed NO production at least in part by iNOS down-regulation. These in vitro anti-inflammatory effects of EBP and $\mathrm{BL}$ were well correlated with the anti-inflammatory activities of the constituents, papyriflavonol A and broussochalcone A.

The enhancing anti-inflammatory effect of $B L$ was also found in several in vivo experiments. Against AA-induced ear edema test, a 5-LOX inhibitor-sensitive animal model of acute inflammation (Inoue et al., 1988), EBP strongly inhibited edematic response, suggesting 5-LOX inhibitory action in vivo. $\mathrm{BL}$ clearly showed the enhancing response when compared to treatment of either EBP or ELJ alone. On CGN-induced paw edema, BL also showed the potent inhibition. The exact reason for these enhancing effects of $\mathrm{BL}$ is not known yet; however, it is reasonably speculated that the constituents in both extracts act synergistically. The major constituents in EBP are prenylated flavonoids and the majors of ELJ are hederagenin and iridoid derivatives (Lee et al., 1995; Son et al., 2001; Kwak et al., 2003a). These constituents may synergistically and cooperatively act at multiple points (5-LOX, COX-2, iNOS, etc.) in complex inflammatory pathways of in vivo experimental models tested. Lin et al. (2008) claimed that the major active principles of the ethanol extract of $B$. papyrifera were betulin and betulinic acid and that these compounds inhibited the vascular permeability via autocrines and nitric oxide. On the other hand, our preparation (EBP and BL) interfered with the pathways of eicosanoid and nitric oxide production. Indeed, 5-LOX products such as leukotrienes and $\mathrm{COX}$ products such as $\mathrm{PGE}_{2}$ are major players that lead to the production of edematic response in AA-induced ear edema and $5 \mathrm{~h}$ CGN-paw edema models (Vinegar et al., 1969; Holsapple and Yim, 1984; Inoue et al., 1988; Damas et al., 1990). Accordingly, the strong anti-inflammatory activity of EBP and BL in these animal models of inflammation may be associated with their inhibitory effects on 5-LOX, COX and iNOS. EBP and BL showed strong activity against both models, suggesting their broad anti-inflammatory activity.

In conclusion, EBP, ELJ and BL were found to exert significant anti-inflammatory activity in vitro and in vivo. Especially, BL showed potent and enhancing effects in several animal models of inflammation. The 5-LOX, COX-2 and iNOS inhibitory actions of these preparations contributed to anti-inflammatory action in vivo. Taken together, these results suggest that EBP and BL may be safely used for the treatment of human inflammatory disorders.

\section{ACKNOWLEDGMENTS}

This investigation was financially supported from Ministry of Knowledge Economy (Korea) (2009-1010) and post BK-21 project from the Ministry of Education (Korea) and greatly acknowledged. The authors would like to thank Pharmacal Research Institute and Central Laboratory 
(KNU) for the use of bioassay facilities.

\section{REFERENCES}

Chen, R. M., Hu, L. H., An, T. Y., Li, J. and Shen, Q. (2002). Natural PTP1B inhibitors from Broussonetia papyrifera. Bioorg. Med. Chem. Lett. 12, 3387-3390.

Cheng, Z. J., Lin, C. N., Hwang, T. L. and Teng, C. M. (2001). Broussochalcone $A$, a potent antioxidant and effective suppressor of inducible nitric oxide synthase in lipopolysaccharide-activated macrophages. Biochem. Pharmacol. 61, 939-946.

Chi, Y. S., Cheon, B. S. and Kim, H. P. (2001a). Effect of wogonin, a plant flavone from Scutellaria radix, on the suppression of cyclooxygenase and the induction of inducible nitric oxide synthase in lipolpolysaccharide-treated RAW 264.7 cells. Biochem. Pharmacol. 61, 1195-1203.

Chi, Y. S., Jong, H. G., Son, K. H., Chang, H. W., Kang, S. S. and Kim, H. P. (2001b). Effects of naturally occurring prenylated flavonoids on arachidonic acid metabolizing enzymes: Cyclooxygenases and lipoxygenases. Biochem. Pharmacol. 62, 1185-1191.

Damas, J., Bourdon, V., Remacle-Volon, G. and Adam, A. (1990). Kinins and peritoneal exudates induced by carrageenin and zymosan in rats. Br. J. Pharmacol. 101, 418-422.

Editorial Committee of Zhong Hua Ben Cao of State Administration of Traditional Chinese Medicine of People's Republic of China (1999). Zhong Hua Ben Cao vol. 2., pp. 473-474, Shanghai Science and Technology Publishing Co, Shanghai.

Holsapplae, M. P. and Yim, G. K. (1984). Therapeutic reduction of ongoing carrageenin-induced inflammation by lipoxygenase, but not cyclooxygenase inhibitors. Inflammation 8, 223-230.

Hwang, J. H. and Lee, B. M. (2007). Inhibitory effects of plant extracts on tyrosinase, L-DOPA oxidation, and melanin synthesis. J. Toxicol. Environ. Health A 70, 393-407.

Inoue, H., Mori, T. and Koshihara, Y. (1988). Sulfidopeptideleukotrienes are major mediators of arachidonic acid-induced mouse ear edema. Prostaglandins 36, 731-739.

Kawai, H., Kutoyanagi, M. and Ueno, A. (1988). Iridoid glucosides from Lonicera japonica thunb. Chem. Pharm. Bull. 36, 3664-3666.

Kim, H. K., Namgoong, S. Y. and Kim, H. P. (1993). Anti-inflammatory activity of flavonoids: Mice ear edema inhibition. Arch. Pharm. Res. 16, 18-24.

Kwak, W. J., Han, C. K., Chang, H. W., Kim, H. P., Kang, S. S. and Son, K. H. (2003a). Loniceroside C, an anti-inflammatory saponin from Lonicera japonica. Chem. Pharm. Bull. 51, 333-335.

Kwak, W. J., Moon, T. C., Lin, C. X., Rhyn, H. G., Jung, H., Lee, E., Kwon, D. Y., Son, K. H., Kim, H. P., Kang, S. S., Murakami, M., Kudo, I. and Chang, H. W. (2003b). Papyriflavonol A from Broussonetia papyrifera inhibits the passive cutaneous anaphylaxic reaction and has a secretory phospholipase $\mathrm{A}_{2}$ inhibitory activity. Biol. Pharm. Bull. 26, 299-302.

Lee, S. J., Shin, E. J., Son, K. H., Chang, H. W., Kang, S. S. and Kim, H. P. (1995). Anti-inflammatory activity of the major constituents of Lonicera japonica. Arch. Pharm. Res. 18, 133-135.

Lee, S. J., Son, K. H., Chang, H. W., Kang, S. S. and Kim, H. P. (1998). Anti-inflammatory activity of Lonicera japonica. Phytother. Res. 12, 445-447.

Lin, L. W., Chen, H. Y., Wu, C. R., Liao, P. M., Lin, Y. T., Hsieh, M. T. and Ching, H. (2008). Comparison with various parts of Broussonetia papyrifera as to the antinociceptive and anti-inflammatory activities in rodents. Biosci. Biotechnol. Biochem. 72, 2377-2384.

Mossman, T. (1983). Rapid colorimetric assay for cellular growth and survival: application to proliferation and cytotoxic assays. J. Immunol. Methods 65, 55-63.

Qian, Z. M., Li, H. J., Li, P., Chen, J. and Tang, D. (2007). Simultaneous quantification of seven bioactive components in Caulis Lonicera japonicae by high performance liquid chromatography. Biomed. Chromatogr. 21, 649-654.

Shougakukan. (1985). The dictionary of Chinese drugs. vol. 3. pp. 2027-2029. Shanghai Science and Technologic Publishers and Shougakukan, Tokyo.

Son, K. H., Kwon, S. J., Chang, H. W., Kim, H. P. and Kang, S. S. (2001). Papyriflavonol A, a new prenylated flavonoid from Broussonetia papyrifera. Fitoterapia 72, 456-458.

Tries, S., Neupert, W. and Laufer, S. (2002). The mechanism of action of the new anti-inflammatory compound ML3000: inhibition of 5-LOX and COX-1/2. Inflamm. Res. 51, 135-143.

Vinegar, R., Schreiber, W. and Hugo, R. (1969). Biphasic development of carrageenin edema in rats. J. Pharmacol. Exp. Ther. 166, 96-103.

Wang, J. P., Tsao, L. T., Raung, S. L. and Lin, C. N. (1997). Investigation of the inhibitory effect of broussochalcone $A$ on respiratory burst in neutrophils. Eur. J. Pharmacol. 320, 201-208.

Winter, C. A., Risley, E. A. and Nuss, G. W. (1962). Carrageenan-induced edema in the hindpaw on the rat as an assay for anti-inflammatory drugs. Proc. Soc. Exp. Biol. Med. 111, 544-547. 